ON the basis that ozone $\left(\mathrm{O}_{3}\right)$ can upregulate cellular antioxidant enzymes, a morphological, biochemical and functional renal study was performed in rats undergoing a prolonged treatment with $\mathrm{O}_{3}$ before renal ischaemia. Rats were divided into four groups: (1) control, a medial abdominal incision was performed to expose the kidneys; (2) ischaemia, in animals undergoing a bilateral renal ischaemia $(30 \mathrm{~min})$, with subsequent reperfusion $(3 \mathrm{~h})$; (3) $\mathrm{O}_{3}+$ ischaemia, as group 2 , but with previous treatment with $\mathrm{O}_{3}\left(0.5 \mathrm{mg} / \mathrm{kg}\right.$ per day given in $\left.2.5 \mathrm{ml} \mathrm{O} \mathrm{O}_{2}\right)$ via rectal administration for 15 treatments; (4) $\mathrm{O}_{2}+$ ischaemia, as group 3 , but using oxygen $\left(\mathrm{O}_{2}\right)$ alone. Biochemical parameters as fructosamine level, phospholipase $A$, and superoxide dismutases (SOD) activities, as well as renal plasma flow (RPF) and glomerular filtration rate (GFR), were measured by means of plasma clearance of $p$-amino-hippurate and inulin, respectively. In comparison with groups 1 and 3 , the RPF and GFR were significantly decreased in groups 2 and 4. Interestingly, renal homogenates of the latter groups yielded significantly higher values of phospholipase $A$ activity and fructosamine level in comparison with either the control (1) and the $\mathrm{O}_{3}(3)$ treated groups. Moreover renal SOD activity showed a significant increase in group 3 without significant differences among groups 1, 2 and 4. Morphological alterations of the kidney were present in $100 \%, 88 \%$ and $30 \%$ of the animals in groups 2,4 and 3 , respectively. It is proposed that the $\mathrm{O}_{3}$ protective effect can be ascribed to the substantial possibility of upregulating the antioxidant defence system capable of counteracting the damaging effect of ischaemia. These findings suggest that, whenever possible, ozone preconditioning may represent a prophylactic approach for minimizing renal damage before transplantation.

Key words: Warm ischaemia; Reperfusion; Reactive oxygen species; Superoxide dismutase; Ozonetherapy

\section{Prevention of renal injury after induction of ozone tolerance in rats submitted to warm ischaemia}

\author{
E. Barber, ${ }^{1}$ S. Menéndez, ${ }^{2}$ O. S. León, ${ }^{3}$ \\ M. O. Barber, ${ }^{1}$ N. Merino, ${ }^{3}$ J. L. Calunga, ${ }^{2}$ E. Cruz ${ }^{1}$ \\ and V. Bocci ${ }^{4}, \mathrm{CA}$
}

${ }^{1}$ Institute of Basic and Preclinical Sciences 'Victoria de Girón', Havana; ${ }^{2}$ Ozone Research Centèr, P.O. Box 6880, Havana; ${ }^{3}$ National Center for Scientific

Research, Havana, Cuba; ${ }^{4}$ Institute of General

Physiology, University of Siena, Via Laterina 8, 53100 Italy
${ }^{\mathrm{CA}}$ Corresponding Author Tel: (+39) 577263856 Fax: (+39) 577263861
Email: fisgen@unisi.it

\section{Introduction}

Tissue ischaemia followed by reperfusion with oxygenated blood occurs in a number of clinical situations. In order to improve the success rate of renal transplantation, the timing of warm and cold ischaemia is a major determinant for the kidney's viability. ${ }^{1,2}$ After reimplantation, owing to reperfusion with oxygenated blood, the ischaemic kidney may develop tubular necrosis and the recipient needs to undergo dialysis. Furthermore, in order to avoid rejection, treatment with immunosuppressor drugs may, on one side worsen the renal damage, or become overtly toxic. ${ }^{1}$ Thus any prophylactic approach aiming at preserving the kidney is of a crucial importance. Recent advances in understanding the fundamental mechanisms of post-ischaemic injury have suggested that tissue injury is associated with higher oxygen $\left(\mathrm{O}_{2}\right)$ tension in the tissue at the time of reperfusion. ${ }^{2,3}$ The reoxygenation leads to a massive production of reactive oxygen species (ROS), generated through several cytoplasmatic or mitochondrial mechanisms, inducing an unbalance between oxidants and antioxidants, i.e. an oxidant stress, which contributes to tissue injury..$^{2,4-6}$ ROS among which superoxide anion $\left(\mathrm{O}_{2}{ }^{-\bullet}\right)$ hydrogen peroxide $\left(\mathrm{H}_{2} \mathrm{O}_{2}\right)$, hydroxyl radical $\left(\mathrm{OH}^{\circ}\right)$, not only can damage cells by oxidizing nucleic acids, proteins and polyunsaturated lipids, ${ }^{7}$ but may ultimately lead to cell death. There is no doubt that ROS, if unquenched, can compromise renal function by impairing glomerular filtration and tubular reabsorption. ${ }^{8}$

In normal conditions, cells contain a powerful and articulate endogenous defence against $\operatorname{ROS}^{9}$ such as 
antioxidant enzymes, namely superoxide dismutases (SOD), catalase, glutathione peroxidase, thioredoxin reductase, or nonenzymatic components such as ascorbic and uric acid, reduced glutathione, $\beta$-carotene, lycopene, vitamin $\mathrm{E}$, bilirubin, etc. ${ }^{2,8,9}$ In several pathologic situations and after ischaemia, these defence mechanisms can be overwhelmed allowing the ROS to exert their deleterious effect. ${ }^{2}$

Taking into account that ischaemia-reperfusion is a process largely mediated by ROS generation ${ }^{2-6}$ and that a prolonged and judicious administration of $\mathrm{O}_{3}$ is able to stimulate the endogenous antioxidant systems, ${ }^{11-14}$ and thereby to oppose the oxidative stress, we thought it worthwhile assessing renal morphology and function and a few biochemical parameters in rats undergoing a controlled, warm renal ischaemia.

\section{Materials and methods}

\section{Animals and sample preparation}

Forty adult male Wistar rats (250-260g) were maintained in an air filtered and temperature conditioned room $\left(20-22^{\circ} \mathrm{C}\right)$ with a relative humidity of $50-52 \%$. Rats were fed with a standard commercial diet and water ad libitum. $\mathrm{O}_{3}$ was generated by an OZOMED equipment (Ozone Research Center, Cuba), from medical grade oxygen by means of a silent electric discharge, representing about $3 \%$ of the gas mixture $\left(\mathrm{O}_{3}+\mathrm{O}_{2}\right)$. Rats received 15 ozone treatments, by rectal insufflation, performed with a suitable polythene cannula connected to a syringe, once daily, $2.5-2.6 \mathrm{ml}$ with $\mathrm{O}_{3}$ concentration of $50 \mu \mathrm{g} / \mathrm{ml}$ (representing a dose of $0.5 \mathrm{mg} / \mathrm{kg}$ weight), before the renal ischaemiareperfusion damage. This schedule and $\mathrm{O}_{3}$ dosing has proved to be optimal in a previous study. ${ }^{13}$

Under constant sodium pentobarbital anaesthesia, after a renal ischaemia of $30 \mathrm{~min}$, we allowed a reperfusion period of exactly $3 \mathrm{~h}$. Heparin $(50 \mathrm{U})$ was administered via the subcutaneous route. Immediately thereafter, within the following $10 \mathrm{~min}$ we assessed the renal plasma flow (RPF) and the glomerular filtration rate (GFR) by means of plasma clearance of p-amino-hippurate (PAH) and inulin, respectively. A constant plasma concentration of both substances was used ( $2 \mathrm{mg}$ of PAH and $20 \mathrm{mg}$ of inulin in $100 \mathrm{ml}$ of saline solution) by a continuous perfusion through the left femoral vein at a rate of $0.15 \mathrm{ml} /$ min, after a loading dose of $0.8 \mathrm{ml}$ of PAH $(12 \mathrm{mg} / \mathrm{ml})$ and $0.8 \mathrm{ml}$ of inulin $(2 \mathrm{mg} / \mathrm{ml})$. For these analyses, blood was withdrawn by intracardiac puncture and urine were collected from the bladder. Thereafter the rats were euthanized under deep anaesthesia. Representative samples of different kidney portions were taken for histopathological studies and tissue homogenates. Kidney homogenates were obtained using a tissue homogenator Edmund Bulher LBMA at $4^{\circ} \mathrm{C}$. The homogenates were prepared in $50 \mathrm{mM} \mathrm{KCl} /$ histidine buffer $\mathrm{pH} 7.4,1: 10(\mathrm{w} / \mathrm{v})$ and were spun down with a Sigma Centrifuge $2 \mathrm{~K} 15$, at $4^{\circ} \mathrm{C}$ and $8500 \times \mathbf{g}$ for $20 \mathrm{~min}$. The supernatants were used for biochemical determinations.

\section{Treatment schedule and renal ischaemia}

The protocol consisted of four experimental groups of 10 animals each as follows: (1) negative group (control): animals were anaesthetized, using sodium pentobarbital at doses of $30 \mathrm{mg} / \mathrm{kg}$ of weight, receiving $50 \mathrm{IU}$ of heparin by intraperitoneal injection. Afterwards, a laparotomy was performed for the sham exposure of the kidneys with successive laparorrhaphy; (2) positive group (ischaemia): animals were processed in the same way as group 1, but after the kidney exposition they were submitted to a bilateral renal ischaemia. Both renal arteries were crossclamped for $30 \mathrm{~min}$, with subsequent reperfusion during $3 \mathrm{~h}$, before the morphological, functional and biochemical renal study; (3) $\mathrm{O}_{3}$ group $\left(\mathrm{O}_{2}+\mathrm{O}_{3}\right.$ and ischaemia) received the same procedure as group 2 , but the animals had been treated daily, during the previous 15 days, with insufflation via rectal route, using a gas mixture composed of $\mathrm{O}_{2}+\mathrm{O}_{3}$; (4) $\mathrm{O}_{2}$ group $\left(\mathrm{O}_{2}\right.$ and ischaemia) with the same procedure of group 3 , but insufflating only $\mathrm{O}_{2}(13 \mathrm{mg} / \mathrm{kg}$ weight) instead of the gas mixture composed of $\mathrm{O}_{2}+\mathrm{O}_{3}$.

\section{Biochemical determinations}

PAH and inulin were determined in deproteinated plasma and urine samples by cadmium sulphate, ${ }^{15}$ using for PAH the photocolorimetric technique as modified by Smith and Tinkelstein. ${ }^{16}$ Inulin was measured by the direct method of resorcinol without alkaline treatment. ${ }^{17}$

Kidney homogenates were assayed for total SOD $(\mathrm{Cu} / \mathrm{Zn}$ and $\mathrm{Mn} \mathrm{SOD})$ activity determining the capacity of the enzyme of inhibiting the autoxidation of pyrogallol by $50 \% .{ }^{18}$ The phospholipase A activity was determined according to a standard procedure ${ }^{19}$ and both enzymatic activities have been expressed as U/g protein. The proteins were measured by a standard Coomassie blue method. ${ }^{20}$ Fructosamine was determined by means of a colorimetric procedure ${ }^{21}$ and values represent the difference in units of optical density in respect of renal tissue (g).

\section{Histological study}

Samples of rat kidneys of the different groups were taken and fixed in neutral $10 \%$ formalin, processed and embedded in paraffin. The histological sections, stained with haematoxylin and eosin, were examined by a pathologist unaware of the treatment schedule. Differences among groups were evaluated with a nonparametric test (Fischer's test). 


\section{Statistical analysis}

The statistical analysis was started by using the OUTLIERS preliminary tests for detection of error values. Afterward the Anova method (single way) was used followed by homogeneity variance test (BartlettBox). In addition, a multiple comparison test was used (Duncan's test) and for the comparison of two groups, the Student's $t$-test was done. Values are expressed by the mean \pm standard error $(n=10$ per group). Different letters indicate a statistical significance of at least $P<0.05$.

\section{Results}

Figure 1 shows the renal plasma flow measured by means of the clearance of PAH. A significant decrease of PAH clearance was observed in groups 2 (ischaemia) and 4: $\mathrm{O}_{2}+$ ischaemia) in comparison with either groups 1 (control) or $3\left(\mathrm{O}_{3}+\right.$ ischaemia). Between either groups 2 and 4 or groups 1 and 3 there were no statistically significant differences. Figure 1 shows the GFR measured by means of plasma clearance of inulin. A significant decrease of inulin clearance was observed in groups 2 (ischaemia) and 4 $\left(\mathrm{O}_{2}+\right.$ ischaemia $)$ in comparison with both groups 1 (control) and $3\left(\mathrm{O}_{3}+\right.$ ischaemia). Between either groups 2 and 4 , or groups 1 and 3 there were no statistically significant difference.

Table 1 shows the biochemical parameters measured in kidney homogenates groups 1 to 4 . The phospholipase A activity in the $\mathrm{O}_{3}+$ ischaemia group did not differ from the control group and values were significantly lower in comparison with the ischaemia and $\mathrm{O}_{2}+$ ischaemia treatment groups. No difference was observed between groups 2 and 4 . A similar trend was observed in regard to the fructosamine concentration, that yielded significantly lower values in control and $\mathrm{O}_{3}+$ ischaemia groups in comparison with the ischaemia and $\mathrm{O}_{2}+$ ischaemia groups. No statistical differences between groups 1 and 3 and between groups 2 and 4 were observed. As was expected, the renal SOD activity showed a significant increase in the $\mathrm{O}_{3}+$ ischaemia group only in comparison with control, ischaemia and $\mathrm{O}_{2}+$ ischaemia.

Morphological alterations (cortical-medullar haemorrhage, mitochondria tumefaction of the tubular epithelium, tubular cell necrosis and dilatation of
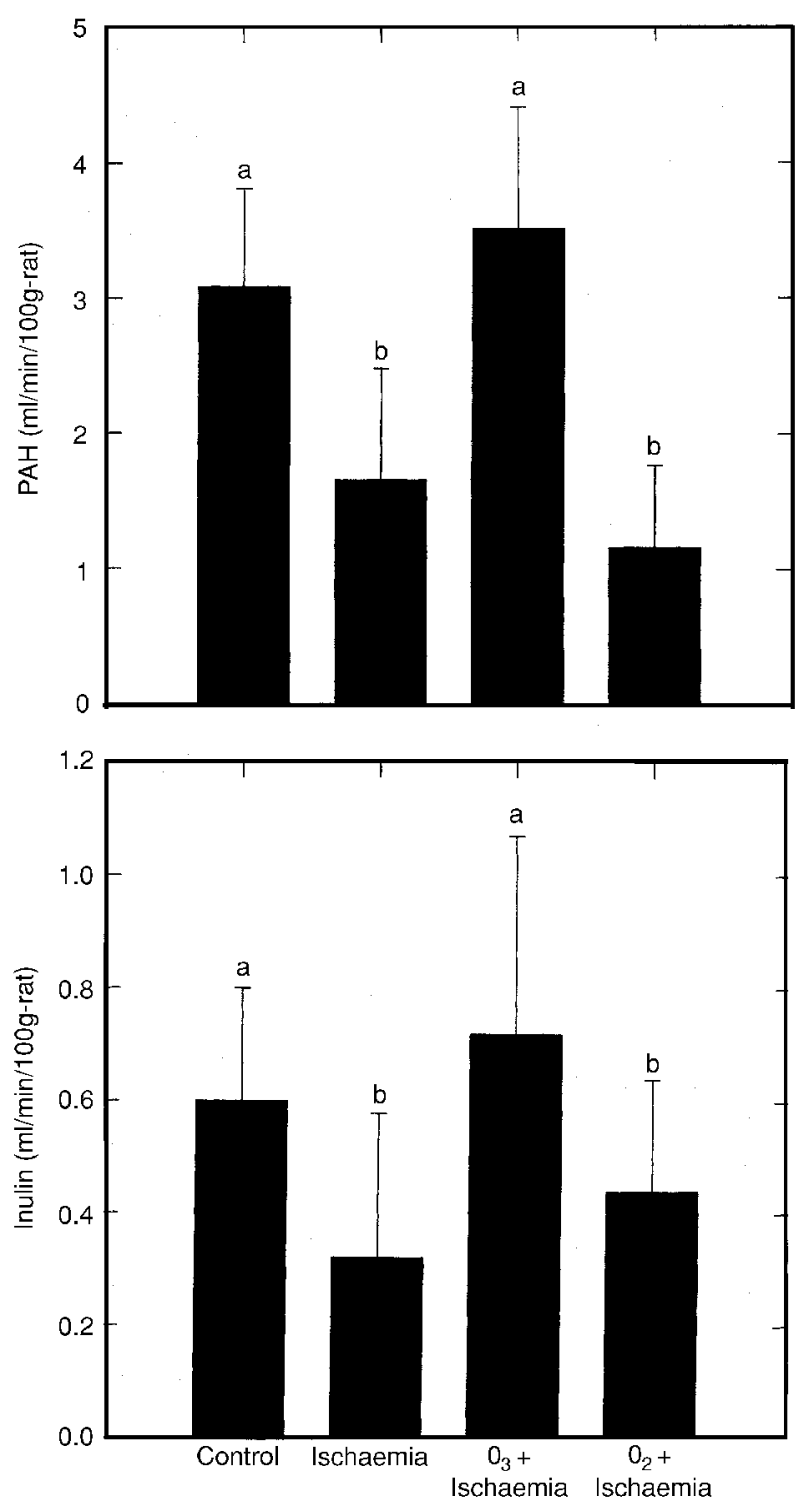

FIG. 1. Plasmatic clearances of p-amino-hippurate (PAH) and inulin in the different groups of treatment. Values represent mean \pm SE. Different letters indicate $P<0.05$.

convoluted tubules were present in $88 \%$ and $100 \%$ of the animals in the groups 2 and 4, respectively, and in only $30 \%$ of group 3 (with minor lesions). A significant statistical difference $(P<0.05)$ was obtained between the ozone group and the ischaemia and oxygen groups. No difference between the ischaemia group and the oxygen group was obtained.

Table 1. Results of the different biochemical parameters measured in the different groups of treatment

\begin{tabular}{lcccc}
\hline Parameters & (1) Control & (2) Ischaemia & (3) $\mathrm{O}_{1}+$ ischaemia & (4) $\mathrm{O}_{2}+$ ischaemia \\
\hline Phospholipase A & $22.4 \pm 12.25^{\mathrm{a}}$ & $104.7 \pm 53.7^{\mathrm{b}}$ & $33.7 \pm 9.2^{\mathrm{a}}$ & $92.5 \pm 21.6^{\mathrm{b}}$ \\
Fructosamine & $0.013 \pm 0.002^{\mathrm{a}}$ & $0.020 \pm 0.005^{\mathrm{b}}$ & $0.015 \pm 0.002^{\mathrm{a}}$ & $0.019 \pm 0.001^{\mathrm{b}}$ \\
SODs & $742 \pm 182^{\mathrm{a}}$ & $964 \pm 184^{\mathrm{a}}$ & $1407 \pm 142^{\mathrm{b}}$ & $996 \pm 128^{\mathrm{a}}$ \\
\hline
\end{tabular}

Statistical significance between a and b of at least $P<0.05$. 


\section{Discussion}

It has been demonstrated that the induction of controlled stress conditions to cardiac cells produces paradoxically positive cell responses, while prolonged ischaemic stress leads to irreversible cardiac cell injury. ${ }^{22,23}$ The so-called 'ischaemic preconditioning' promotes an adaptive mechanism that results in cell protection to a subsequent sustained ischaemic condition, as proven by experimental and clinical data. $^{22,23}$ ROS production, occurring during the ischaemia-reperfusion phenomenon, seems to be a major mechanism of tissue injury. ${ }^{2-6,8,10}$ In this paper we present evidence that the oxidative preconditioning with ozone could prepare the host to face physiopathological conditions mediated by ROS, like those induced by the ischaemia-reperfusion process. Our results support the idea that an activation of the endogenous antioxidant defence system can help the preservation of an organ undergoing ischemia. ${ }^{2,3,10,24,25}$ Previous work from our laboratories $^{11-14}$ has already suggested that a judicious administration of ozone, in spite of its well-known reactivity and toxicity, ${ }^{7}$ is able to induce an 'oxidative stress adaptation, ${ }^{12,14}$ and preserve cellular integrity by controlling processes which generate and neutralise ROS.,23-25 The present results have shown that repeated daily administrations of an optimal dosage of a gas mixture $\left(\mathrm{O}_{2}+\mathrm{O}_{3}\right)$, by rectal insufflation in rats, can generate a sort of tolerance to free radicals released after the experimentally induced ischaemiareperfusion phenomenon. On the contrary, in groups 3 (ischaemia) and $4\left(\mathrm{O}_{2}+\right.$ ischaemia) a significant cellular damage was documented by functional, biochemical and morphological criteria.

Moreover, the significant stimulation of endogenous SOD in the $\mathrm{O}_{3}+\mathrm{ischaemia}$ group suggests that cellular protection is most likely achieved through the reduction in the availability of $\mathrm{O}_{2}{ }^{-}$. Similar to other cells, renal cells respond to many biological stimuli, including ROS, with increased antioxidant enzyme activities. $^{2-4}$ In our experimental situation, the increased SOD values in groups 2 and 4 were statistically not significant. Our data are in line with previous reports, ${ }^{26,27}$ that, to a different degree, have shown increased activities of SOD, catalase and glutathione peroxidases, after chronic $\mathrm{O}_{3}$ exposure. It is truly remarkable that plants can also express a protective response to $\mathrm{O}_{3}$, upregulating the antioxidant defence system so that the redox balance can be readjusted.$^{28}$ Probably one of the most important ROS is $\mathrm{O}_{2}^{-}$, produced by the activity of xantine oxidase (XO). ${ }^{29}$ Normally cells contain xanthine dehydrogenase (XDH) that catalyses the conversion of xanthine (or hypoxanthine) to uric acid. XDH can be converted to $\mathrm{XO}$ as a result of sulphydryl oxidation, or in vivo after ischaemia-reoxygenation injury. ${ }^{4} \mathrm{XO}$, in the presence of molecular oxygen, also converts xanthine to uric acid but with the formation of $\mathrm{O}_{2}{ }^{-}$. In addition, the XO generated ROS may be important in glomerular injury. $\mathrm{O}_{2}^{-}$is dismutated by SOD to $\mathrm{H}_{2} \mathrm{O}_{2}$, that is not a free radical, but is still a powerful oxidant. Moreover, even in the presence of traces of $\mathrm{Fe}^{2+}, \mathrm{H}_{2} \mathrm{O}_{2}$ can be transformed into the deleterious $\mathrm{OH}^{*}$ by the Fenton reaction. Because of the wide distribution of chloride ion in biologic systems, the formation of hypochlorous acid ( $\mathrm{HOCl}$ ) is another significant product, being a highly reactive toxic species. $\mathrm{O}_{2}^{-\bullet}$ can also react with nitric oxide $\left(\mathrm{NO}^{-}\right)$ producing peroxynitrite ( $\mathrm{ONOO}^{\circ}$ ) being highly toxic to cells. Antioxidant enzymes operate via several protective mechanisms: as an interesting example, rapid dismutation of $\mathrm{O}_{2}^{-\cdot}$ to $\mathrm{H}_{2} \mathrm{O}_{2}$, by depleting $\mathrm{O}_{2}{ }^{-\bullet}$ levels, on one side minimises the formation of $\mathrm{ONOO}^{-}$and on the other side spares NO that acts as a potent vasodilator of the renal circulation.

Critical evidence for the protective role of endogenous SOD has been recently provided in a study using transgenic mice overexpressing a SOD gene. ${ }^{30}$ Also Paller et al. ${ }^{31}$ demonstrated that treatment of rats with SOD or allopurinol, reduce renal injury after ischaemia. Thus, enhanced local antioxidant enzyme activities provided the kidney with an effective defence system against the toxic effect of ROS. PhospholipaseA activity in group 3 was slightly above control values but significantly lower than values of groups 2 and 4 , indicating that $\mathrm{O}_{3}$ exerted indirectly a protection against the cellular disruption, mediated by an enzyme which, after activation, generates lysophospholipids and other metabolites responsible of cellular lysis. The increased phospholipase activity in groups 2 and 4 suggests that the enzyme may be partly responsible for the kidney damage noted in the morphological study. The evaluation of fructosamine levels gives us an indirect measure of the oxidative stress, because it accelerates protein glycosylation ${ }^{20,32}$ thus yielding higher fructosamine levels than the control ones, exactly as has been found in groups 2 and 4 . Finally in group $3\left(\mathrm{O}_{3}+\right.$ ischaemia) the renal function remains unperturbed and it appears that the $\mathrm{O}_{3}$ treatment has been able to enhance the antioxidant system minimizing the oxidative stress during reperfusion.

In conclusion, although ozone is potentially toxic, when used in therapeutic fashion can upregulate the expression of antioxidant enzymes, a novel property that is hardly achievable with another therapeutic approach. ${ }^{12,14}$ Consequently, whenever possible, ozone therapy may become an important prophylactic treatment able to improve the success of organ transplantation.

\section{References}

1. Belzer FO, Southard JH. Principles of solid organ preservation by cold storage. Transplantation 1988; 45: 673-680.

2. Franssen C, Defraigne JO, Detry O, Pincemail J, Deby C, Lamy M. Antioxidant defense and free radical production in a rabbit model of kidney ischemia-reperfusion. Transplant Proc 1995; 27: 2880-2883. 
3. Meloy RN, Hill KE, Ayon MA, Stein JH. Oxidant stress following renal ischemia. Changes in glutathione redox rats kidney. Kidney Int 1988; 33: 812-816.

4. McCord JM. Oxygen derived free radicals in post ischemic tissue injury. N Engl J Med 1985; 312: 159-163.

5. Cross CE, Halliwell B, Borish ET, et al. Oxygen radicals and human disease. Ann Intern Med 1987; 107: 526-545.

6. Parks PA, Bulky GB. Role of oxygen free radicals in shock, ischemia and organ preservation. Surgery 1983; 94: 428-432.

7. Pryor WA. Mechanisms of radical formation from reactions of ozone with target molecules in the lung. Free Radical Biol Med 1994; 17: 451-465.

8. Yoshioka T, Bills T, Moore-Jarrett T, Greene HL, Burr IM, Ichikawa I. Role of intrinsic antioxidant enzymes in renal oxidant injury. Kidney Int 1990 ; 38: $282-288$.

9. Halliwell B. Antioxidants in human health and disease. Ann Rev Nutr 1996; 16: 33-50.

10. Southard JH, Marsh DC. Oxygen derived free radicals damage in organ preservation. Activity of superoxide dismutase and xantine oxidase. Surgery 1987; 101: 566-570.

11. Hernández F, Menéndez S, Wong R. Decrease of blood cholesterol and stimulation of antioxidative response in cardiopathy patients treated with endovenous ozone therapy. Free Radical Biol Med 1995; 1: 115-119.

12. Bocci V. Ozone as a bioregulator: pharmacology and toxicology of ozonetherapy today. J Biol Regul Homeost Agent 1996; 10: 31-53.

13. León OS, Menéndez S, Merino N, et al. Ozone oxidative preconditioning: a protection against cellular damage by free radicals. Mediators Inflamm 1998; 7: 289-294.

14. Bocci V. Is ozone therapy therapeutic? Perspect Biol Med 1998: 42: $131-143$.

15. Fujita A, Iwatoki D. Biochem. Ztschr., 242, 43, 1931. In: Smith HW, eds. Principios de la Fisiología Renal. Spain: Ateneo S.A., 1963.

16. Smith HW, Tinkelstein N. The renal clearance of substituted hipuric acid derivatives and other aromatic acids in dog and man. J Clin Invest 1945; 24: 388-391.

17. Schreiner G. Determination of inulin by means of resorcinol. Proc Soc Exp Biol Med 1950; 70: 726-730.

18. Boehringer Mannheim. Biochemica Information. A revised biochemical reference source. Enzymes for routine (1st edition), Germany: Boehringer Mannheim, 1987: 80-81.

19. Hotter G, León OS, Catafau-Roselló J, et al. Tissular prostanoid release phospholipase A2 activity and lipid peroxidation in pancreas transplantation. Transplantation 1991; 51: 987-990.

20. Spector T. Refinement of the coomasie blue method of protein quantifications. Anal Biochem 1978; 86: 142-146.
21. Thome J, Münch G, Müller R, et al. Advanced glycation endproductsassociated parameters in the peripheral blood of patients with Alzheimer's disease. Life Sci 1996; 59: 679-685.

22. Murry CE, Jennings RB, Reimer KA. Preconditioning with ischemia: a delay of lethal cell injury in ischemic myocardium. Circulation 1986; 74 : 1124-1136.

23. Loeper J, Goy J, Rozensztain L, Bedu O, Moisson P. Lipid peroxidation and protective enzymes during myocardial infarction. Clin Chim Acta 1991; 196: 119-123

24. Nayak MS, Kita M, Marmon MF. Protection of rabbit retins from ischemic injury by superoxide dismutase and catalase. Invest Ophthalmol Visual Sci 1993; 34: 2018-2123.

25. Coudray C, Bouchert F, Pucheu S, De Leiris J, Favier A. Relationship between severity of ischemia and antioxidants scavenger enzyme activities in the isolated rat heart. Int I Biochem Cell Biol 1995; 27 : 61-67.

26. Rahman I, Clerch LB, Massaro D. Rat lung antioxidant enzyme induction by ozone. Am J Physiol 1991; 260: L412-L418.

27. Weller BL, Crapo JD, Slot J, Posthuma G, Plopper CG, Pinkerton KE. Siteand cell-specific alteration of lung copper/zinc and manganese superoxide dismutases by chronic ozone exposure. Am J Respir Cell Molec Biol 1997; 17: 552-560.

28. Sharma YK, Davis KR. The effects of ozone on antioxidant responses in plants. Free Rad Biol Med 1997; 23: 480-488.

29. Knight JA. Diseases related to oxygen-derived free radicals. Ann Clin Lab Sci 1995; 25: 11-121.

30. Wang $\mathrm{P}$, Chen $\mathrm{H}$, Qin $\mathrm{H}$, et al. Overexpression of human copper, zincsuperoxide dismutase (SOD1) prevents postischemic injury. Proc Natl Acad Sci 1998; 95: 4556-4560.

31. Paller MS, Hoidal JR, Ferris JF Oxygen free radicals in ischemic acute renal failure in the rat. J Clin Invest 1984; 74: 1156-1164.

32. Johnson RN, Metcalf PA, Baker JA. Fructosamine: a new approach to the estimation of serum glycosylprotein. An index of diabetic control. Clin Chim Acta 1982; 127: 87-94.

ACKNOWLEDGEMENTS. Mrs Helen Carter and Patrizia Marrocchesi are thanked for carefully editing the manuscript. A partial support by Murst national (40\%) and local (60\%) funds to V.B. is acknowledged.

\section{Received 2 November 1998; accepted in revised form 18 December 1998}




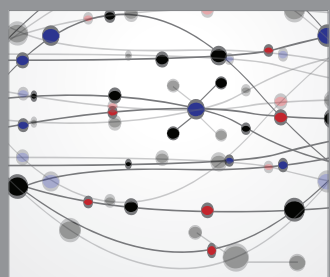

The Scientific World Journal
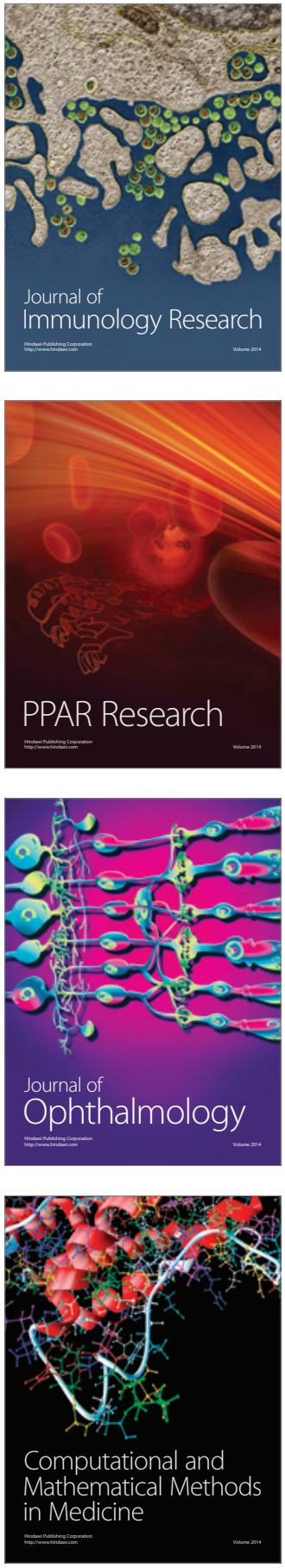

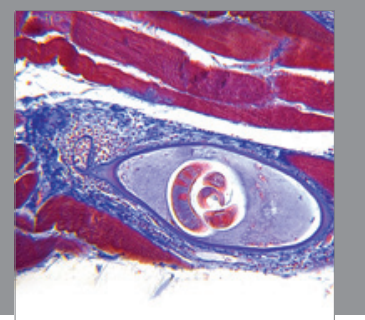

Gastroenterology

Research and Practice
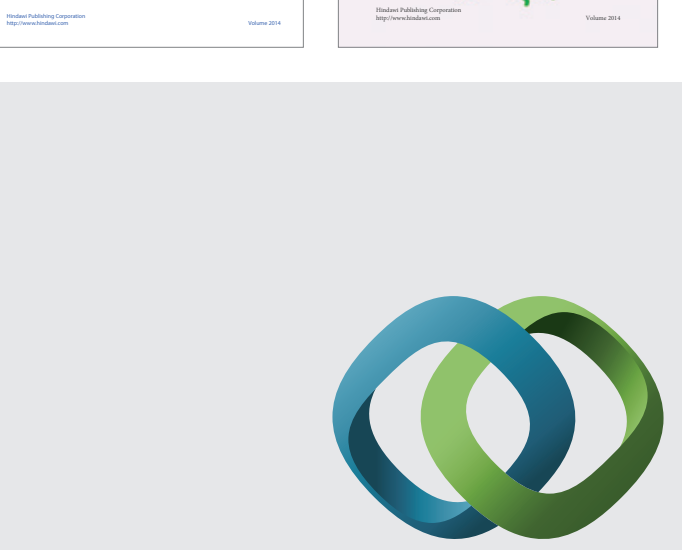

\section{Hindawi}

Submit your manuscripts at

http://www.hindawi.com
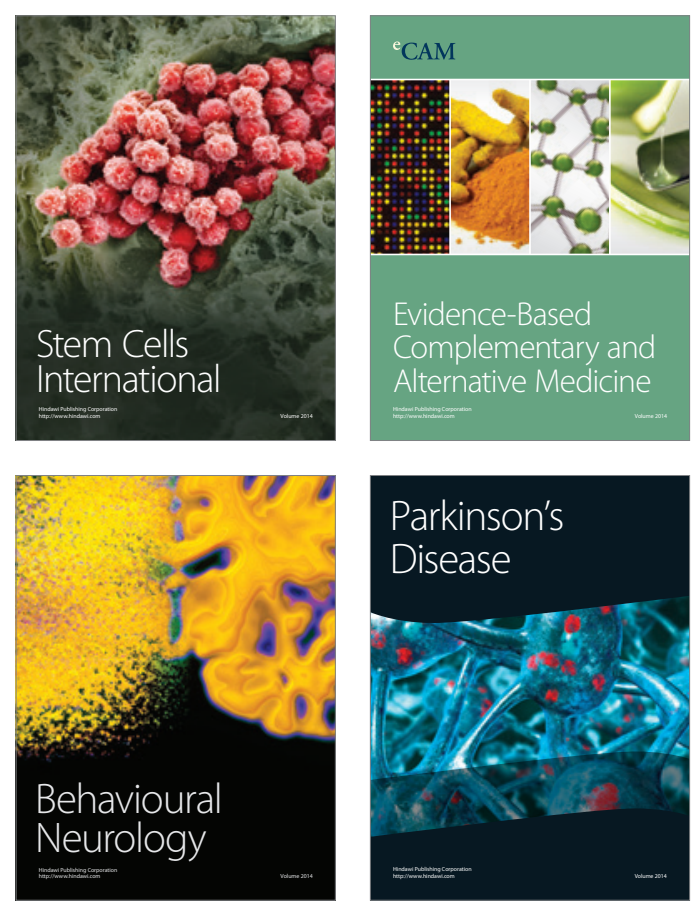

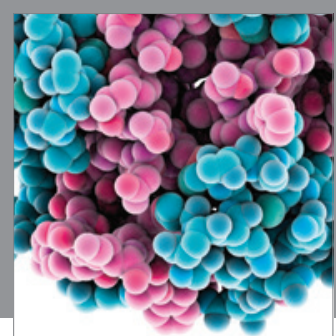

Journal of
Diabetes Research

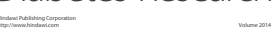

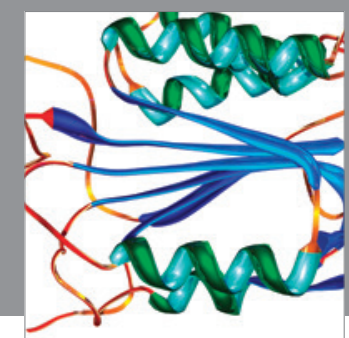

Disease Markers
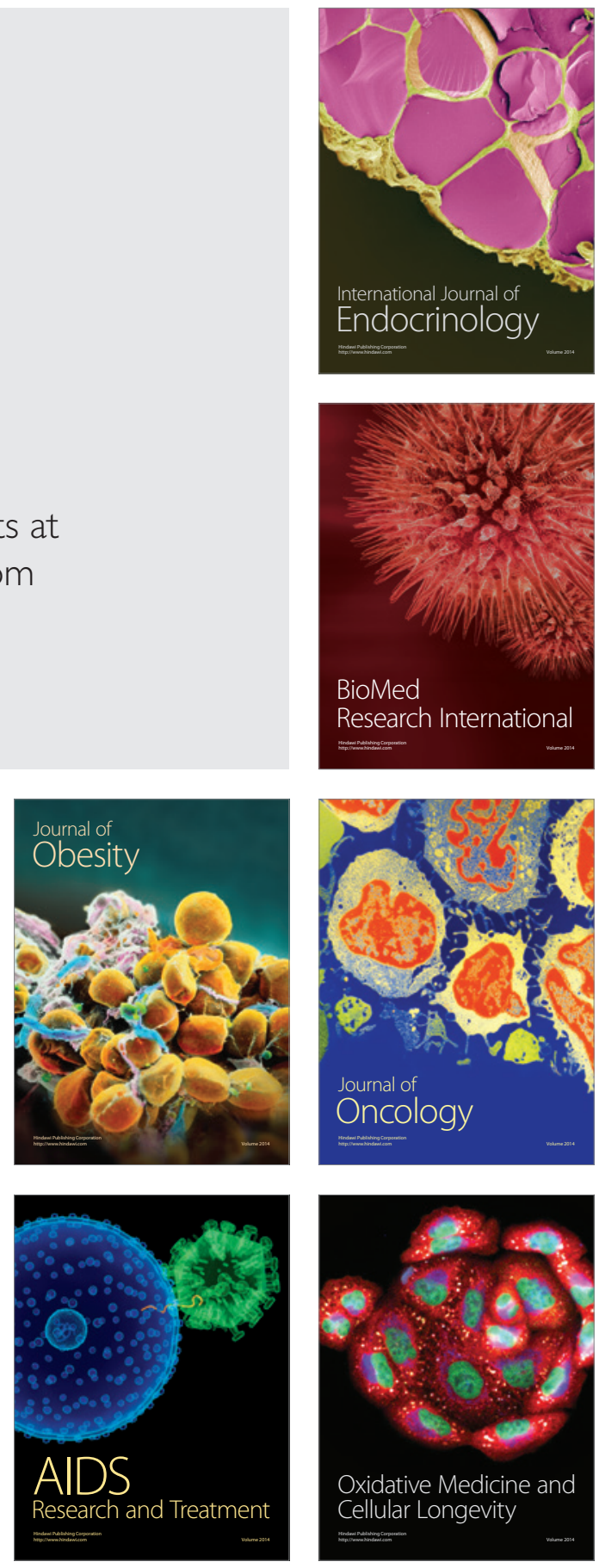